\title{
Current Trends in Welding Flux Development
}

\author{
A. D. Adeyeye* \\ Department of Industrial and Production Engineering, Faculty of Technology, University of Ibadan, Oyo State, NIGERIA.
}

\begin{abstract}
Welding flux makes significant contribution to weld-metal quality, productivity of welding process and rapid deployment of new materials. Deployment of new materials has been hampered because of lengthy trial-and-test experiments and paucity of methodology for modelling and optimisation in the traditional welding flux development. This paper discussed the contributions made to mitigate the drawbacks of traditional welding flux development in areas of experimentations, prediction modelling and optimisation. Limitations of current efforts were identified and suggested for future research, namely (i) current response models are limited to well-behaved flux systems and do not account for edge and additive effects of flux ingredients (ii) non-incorporation of stakeholder's preferences concerning the relative importance of quality attributes (iii) lack of prediction and optimisation tools for determining optimal coating factor and flux heights for Shielded Metal Arc Welding and Submerge Arc Welding respectively and (iv) non-continuous response functions and concave regions of the trade-off surface are not considered.
\end{abstract}

Keywords: multiple response optimization, welding flux design, feasible criterion space, flux quality attributes, prediction modelling

\section{INTRODUCTION}

Interest of researchers have been on the increase in welding flux development since the early 1900s when research publications on welding flux development became very visible in the open literature [1]. Many reasons are responsible for this, namely (i) the need to reduce the cost of welding flux (ii) the need to enhance the deployment of new weldable engineering materials (iii) the importance of achieving the required weld-metal quality (iv) the desire to achieve enhanced productivity of the welding process and finally (v) environmental and health issues. For instance, depending on the type of welding process, welding flux accounts for between 10 and $50 \%$ of the total cost of welding [2, 3]. Recycling of fused slag has been suggested as a means of reducing cost of welding flux [4]. The desire to reduce cost has intensified research activities in welding flux development using the waste-to-wealth philosophy [5-9].

The continuous improvement drive in various industries such as in manufacturing, aviation, power, construction, nuclear, petrochemical, etc., requires that new materials be developed to improve high temperature performance, cryogenic performance, corrosion resistance and energy efficiency of machines and operations among others [10]. In response to this, new materials with varying degrees of properties are being developed at a

${ }^{*}$ Corresponding author (Tel: +234 (0) 8029324 164)

Email address: ademola.adadeyeye@gmail.com (A. D. Adeyeye) faster rate than the past [11]. Most of these new materials are designed to be weldable and their deployment depend on the development of appropriate welding fluxes. Adeyeye and Oyawale [10] observed that welding flux development has not kept pace with the rate at which new materials are being developed. This has in a way hampered the deployment of these new materials. To address this lag, researchers have increased efforts at seeking better approaches that will reduce the lead-time for welding flux development.

Another reason for increased research interest in welding flux formulation is because of the numerous and enormous roles welding flux plays in the productivity and operational effectiveness and efficiency of the welding process. The role of welding flux on spatter, deposition rate and efficiency, arc stability, slag detachment, penetration control, and weld-bead geometry have been of interest to welding flux designers (WFD) because they determine the productivity of the welding process $[2,12-17]$. Furthermore, the flux plays major roles in achieving the quality of weld-deposit [18]. Such roles include (i) Protection of molten metal (ii) Weld-metal chemical composition (iii) Mechanical properties of weldment (iv) Microstructural and other metallurgical features (v) Fume generation and its toxicity [8, 17, 19-24].

The selection of appropriate flux ingredients such as $\mathrm{TiO}_{2}$. $\mathrm{CaO}, \mathrm{SiO}_{2}, \mathrm{Al}_{2} \mathrm{O}_{3}, \mathrm{MgO}, \mathrm{MnO}$, and fluorides like $\mathrm{Na}_{2} \mathrm{SiF}_{6}, \mathrm{Na}_{2} \mathrm{TiF}_{6}, \mathrm{~K}_{2} \mathrm{SiF}_{6}$ and $\mathrm{K}^{2} \mathrm{TiF}_{6}$ among others in their right proportions to achieve the numerous requirements is not a trivial problem. The control of weld-metal composi- 
tion to achieve desired properties that meet service requirements is often through the manipulation of the welding flux. For instance, diffusible hydrogen content in weld-metal is a major cause of hydrogen induced cracking in high strength steels [25-28]. Four major methods are used to control and minimise diffusible hydrogen content in weld-metal, namely: (i) increase in basicity index $[29,30]$ (ii) control of oxygen content in weld-metal [25, 31-33] (iii) reduction of partial pressure of hydrogen in the arc atmosphere [25] (iv) reacting hydrogen with elements to produce compounds insoluble in iron [25, 34]. All the aforementioned approaches involve the manipulation of the welding flux chemistry. Similarly, the methods used to control oxygen transfer to weld-metal such as (i) reduction of the oxygen potential of the flux (ii) addition of deoxidants and (iii) increasing the basicity of the flux among others involve the proper design and formulation of the welding flux in terms of the proportions of various ingredients among which are $\mathrm{TiO}_{2}, \mathrm{CaO}, \mathrm{SiO}_{2}, \mathrm{Al}_{2} \mathrm{O}_{3}, \mathrm{MgO}, \mathrm{MnO}$, $\mathrm{FeO}$ and $\mathrm{CaF}_{2}$ [34-36].

In the past, slag generated during welding are dumped as waste. This is no longer the thing todo due to environmental concerns. Slag is a nonbiodegradable by-product of welding and its disposal poses problems such as soil and water pollution. It also takes up a lot of landfill space. Minerals required for the manufacture of welding flux such as calcite, cryolite, rutile, fluorspar, dolomite, quartz, wollastonite, alkaline carbonates and silicates are non-renewable resources and they are getting depleted fast. A lot of research activities are directed towards the development of recycling technology that allows the use of slag as fresh flux to mitigate the above problems and also reduce the total cost of welding $[3,6,7,9]$. A lot of dust (between 10 and $15 \%$ of the flux) is generated during the handling and transportation of flux [5]. The flux dust was usually dumped as waste in the past but in recent years research efforts are directed at developing technologies of making use of it in new fluxes [8, 37]. Welding operations generate gaseous and aerosol by-products consisting of metals, metal oxides in various oxidation states and a number of chemical species that volatilised from the welding wire, flux or base metal. The fume generated may be up to $400 \mathrm{mg} / \mathrm{m}^{3}$ in the rising column of heated air directly above the arc, part of which often get to the breathing zone of the welder. There are lots of adverse health effects on the welder if inhaled. The health concerns have triggered research on how to reduce fume generation, its toxic content and the noxious odours [38-40]. Some of the areas where welding flux plays major roles in achieving good weld quality and enhanced productivity of the welding process are presented in Table 1 . The selection of appropriate flux ingredients in their right proportions to achieve the numerous requirements has been a daunting problem because welding flux ingredients, welding wire constituents and welding process parameters exhibit very complex reactions and interactions during the welding process. It is therefore not surprising that the interest of researchers in welding flux formulation has been growing over the years [4145].

There have been some advancements in the approaches used by researchers to address the aforementioned issues. The advances and contributions started with the work done by Kanjilal et al. [46] and since then there have been a dramatic improvement in the way experiments are conducted, prediction models are developed and optimisation is done. In this paper, the status of welding flux development before 2004 and the trends from 2004 was discussed to provide sufficient understanding and information on the current issues in welding flux development. It will provide insight, enlightenment and references for current research in welding flux formulation and draw attention to areas where future research should focus.

The paper is organized as follows; the trends in the way experiments are designed and conducted is presented in the next section, followed by the description of the approaches for developing prediction models. Next, the advances in optimisation are discussed followed by the directions for future research and the conclusion.

\section{DESIGN AND CONDUCT OF EXPERIMENT 2.1. Traditional Approach to Experimenta- tion}

Prior to 2004 when the first work on application of design of experiment (DoE) to welding flux development appeared, most of the experiments conducted by welding flux researchers and designers were not statistically designed. Adeyeye and Oyawale [75] observed that welding flux development was lagging behind the other areas of arc welding technology in terms of application of DoE. Drawing upon the principles of physics, chemistry and metallurgy tempered with accumulated experience, WFDs formulate an initial flux which they used to weld. Depending on the goal of the study, the operational characteristics and/or weld-metal quality are measured to ascertain their conformity or otherwise to the expected quality requirements. Based on the results, guesses are made to improve the flux relying on the principles of science and accumulated experience. The cycle of 'formulate, weld, test and guess' continued until an acceptable flux was achieved [76-80]. A typical example was the development of welding flux for SMAW of HSLA-100 grade steel by Fleming et al. [76]. A sequential flux formulation methodology was used to study the effects of welding flux type on HSLA-100 steel weld-metal microstructure and mechanical properties. The flux compositions were systematically varied starting with an initial flux that can be classified as rutile-based and ending up with a more basic flux. The objective of the variations was to develop a formulation of a SMAW flux that would exhibit the excellent welding behaviour found typically in a rutile electrode and balanced with the superior weldmetal properties deposited by a basic electrode. 
Table 1: Roles of welding flux in weld-metal quality and welding process productivity.

\begin{tabular}{|c|c|c|c|}
\hline$\overline{\mathbf{S} / \mathbf{N}}$ & $\begin{array}{l}\text { Weld-metal qual- } \\
\text { ity and process } \\
\text { productivity }\end{array}$ & Quality Attributes & Paper \\
\hline 1 & Weld-metal chemistry & $\mathrm{C}, \mathrm{Mn}, \mathrm{N}, \mathrm{Si}, \mathrm{S}, \mathrm{O}_{2}, \mathrm{P}, \mathrm{Ni}, \mathrm{Mo}, \mathrm{Cr}, \mathrm{Ti}$, etc... & {$[8,10,11,19-24,46,47]$} \\
\hline 2 & Microstructure & $\begin{array}{l}\text { Grain size, acicular ferrite, lower bainite, marten- } \\
\text { site, ferrite number etc... }\end{array}$ & {$[8,10,22,23,48-50]$} \\
\hline 3 & Element transfer & Delta $\mathrm{C}, \mathrm{Mn}, \mathrm{Si}, \mathrm{S}, \mathrm{O}_{2}, \mathrm{P}, \mathrm{Ni}, \mathrm{Mo}, \mathrm{Cr}, \mathrm{Ti}, \mathrm{Cu}$, etc... & {$[17,19,23,51-54]$} \\
\hline 4 & Mechanical properties & $\begin{array}{l}\text { Yield strength, Ultimate tensile strength, hard- } \\
\text { ness, \% elongation, impact toughness, etc... }\end{array}$ & $\begin{array}{l}{[6,16,19,21,22,47,49,52,} \\
54-61]\end{array}$ \\
\hline 5 & $\begin{array}{l}\text { Physicochemical and } \\
\text { thermophysical prop- } \\
\text { erties }\end{array}$ & $\begin{array}{l}\text { thermal conductivity, specific heat, thermal diffu- } \\
\text { sivity, wettability, surface tension, etc... }\end{array}$ & {$[9,13,62-67]$} \\
\hline 6 & $\begin{array}{l}\text { Process and operating } \\
\text { productivity }\end{array}$ & $\begin{array}{l}\text { Deposition rate, fusion coefficient, spatter, arc sta- } \\
\text { bility, penetration control, etc... }\end{array}$ & {$[2,12,14,17]$} \\
\hline 7 & Bead morphology & $\begin{array}{l}\text { Bead width, reinforcement, shape factor, weld } \\
\text { cross-sectional area, bead height, etc... }\end{array}$ & {$[15,16,48]$} \\
\hline 8 & $\begin{array}{l}\text { Waste-to-wealth/ En- } \\
\text { vironmental benign }\end{array}$ & Flux consumption, flux dust, used slag, etc... & {$[3,6,21,68-73]$} \\
\hline 9 & Fume (Health issues) & $\begin{array}{l}\text { Fume generation rate, noxious odour, particle } \\
\text { number, mass distribution, particle surface area, } \\
\text { morphology, toxic content of fume }\left(\mathrm{Cr}^{6+}, \mathrm{Mn}, \mathrm{Ni} \text {, }\right. \\
\text { ozone, } \mathrm{Ni}, \mathrm{Si}, \mathrm{Ti}, \mathrm{Si} . .)\end{array}$ & {$[38-42,42-45,74]$} \\
\hline
\end{tabular}

Nine separate series of electrodes were studied each with one substitution for a specific ingredient in the flux. The flux that produced the best results for a given series was used as the basis for the formulation of the next series. The cycle of 'formulate-weld-test-and-guess' was continued involving many iterations until the formulation with acceptable properties for SMAW of HSLA100 steel was achieved.

This approach has many drawbacks [75]. It is technically and economically inefficient due to the trial-and-error nature, long lead-time and consumption of considerable number of man-hours, materials and energy during the extensive experimental flux formulation, weld production and testing. The welding flux developed by this approach has a random character and it is difficult to guarantee optimal formulation [10]. The feasibility or otherwise of achieving the desired compromise formulation cannot be established until a lot of resources and efforts have been expended on lengthy formulate-and-test experiments [18]. The direction and magnitude of interaction effects of welding flux ingredients are difficult to establish. Although the decision of the WFD at each stage is based on principles of science and metallurgy coupled with accumulated experience, it does not completely eliminate bias.

\subsection{The Current Approach to Experimenta- tion}

These drawbacks persisted in the state-of-theart of welding flux design till 2004 when the work of Kanjilal et al. [46] appeared in the literature. The paper opened a new chapter in the state-of-the-art of welding flux development. They used a type of Design of Experiments (DoE) method known as mixture experiment to study the effects of flux ingredients on weld-metal chemistry. Design of experiment has been available for some time and has been used in other areas of arc welding technology especially in the study of welding process parameters on weld-metal quality attributes. Adeyeye and Oyawale [75] provided more information on successful applications of DoE in other areas of arc welding. It appears WFDs were not aware of suitability and efficacy of mixture experiment for welding flux design in the pre-2004 era. The benefits of Statistical Design of Mixture Experiment (SDME) like other DoE approaches are many, namely; (i) It provides reliable information and insight from fewer number of experiments with the attendant reduction in cost and time (ii) The flux ingredient composition space is covered optimally by the various algorithms for choosing the experimental settings (iii) The WFD need not to have a deep knowledge of statistics because software exist to help him determine optimal experimental settings and to perform statistical evaluation of the results (iv) It eliminates the bias that may result from the trialand-test approach (v) It helps the WFD to make more informed decision at each stage of flux development (vi) It allows the WFD to model the relationship between the flux ingredients and the flux quality attributes (vii) It helps the WFD to identify the direction and magnitude of the individual and interaction effects of flux ingredients.

The use of mixture experiment in welding flux design has been on the increase since 2004 [24, $46,47,50,53,62-67,81-85]$. The efficacy and the successful application of mixture experiment has spurred WFDs to further explore the toolkit of DoE to identify the ones suitable for welding flux development. Kanjilal et al. [47] employed an approach known as Rotatable Mixture Design to combine flux ingredients and process parameters (welding current, voltage, speed, electrode polarity) levels. The linearly dependent flux ingredients were converted to independent mixture 
related variables through some transformations. The independent mixture related variables and the welding process parameters were used to develop the design matrix. Ren et al. [86] used a type of DoE known as Uniform Design (UD) to develop welding flux for the multi-arc and high travel speed submerge arc welding (SAW). The UD ensures that the experimental points are uniformly dispersed in the experimental space. Like mixture experiment it also reduces time and cost as well as optimally covering the experimental region. Hadamard Multivariate Design (HMD) was used to develop flux for aluminium welding [55, 87-89]. Nested Random Model (NRM) was employed by Achebo [90] to develop welding flux that meet the required weld-metal quality. Taguchi robust design is another DoE method that has been found very useful in many industries including other areas of arc welding but its applicability in welding flux was only discovered recently and its use in flux development is gaining popularity $[2,5,16,58,60,61,73,91]$. The use of Response Surface Method (RSM) also has been explored recently but its use so far is limited to addition of additives and used slag to new welding flux [6, 21, 23, 59, 89]. The interest in the use of DoE in planning experiments ahead of conducting them will continue to grow in welding flux formulation because of its advantages. Table 2 presents recent approaches and the trends in the application of $\mathrm{DoE}$.

\section{DEVELOPMENT OF PREDICTION MODEL}

\subsection{Traditional Approach to Development of Prediction Models}

The traditional approach for developing models for the prediction of weld-metal properties and welding operational characteristics as a function of flux ingredients is by employing detailed scientific methodologies (kinetics, thermodynamics, slag chemistry, solution thermodynamics, arc plasma physics and chemistry, etc...). These models are cumbersome and not easy to use. The models often consider effects of individual flux ingredients on a single response and not the effects of simultaneous variation of the ingredients on many responses. For instance, Terashina [29] and Surian [30] studied the effect of slag basicity on diffusible hydrogen, Du Plessis and Du Toit [28] studied the effect of flux-oxidizing ingredients on diffusible hydrogen and Du Plessis et al. [27] and Baune et al. [34, 36] investigated the effect of fluoride and calcite on diffusible hydrogen content. Eager [92] and North [35] studied the effects of $\mathrm{FeO}, \mathrm{MnO}$, metallic and ferro-metallic additions on weld-metal oxygen content individually. Farias et al. [93] considered the effects of wollastonite and quatz on fusion rate and short-circuit frequency. In the real-world flux formulation situations, many competing quality requirements are simultaneously considered. For these reasons, models obtained based on physical science principles have limited applications in real-world industrial conditions where it is required that an optimal flux be developed at minimum costs and time.

The reactions and interactions of welding flux ingredients, welding wire constituents and welding process parameters in the weld pool during welding to determine the numerous weld-metal and welding process quality characteristics are complex. There is no theory that has the rigour or sophistication to simultaneously handle the large number of variables that control the welding process and weld-metal quality characteristics. The convectional way to approach such problem is to apply regression analysis in which experimental data are best fitted to some functions. Such functions are expressed in terms of input variables. Other areas of arc welding had been ahead of welding flux development in terms of application of experimental data to perform regression analysis. The reason was because factorial design commonly used in welding process parameters (welding voltage, current, speed, nozzle-to-plate distance, etc...) experiments is not applicable to welding flux experiments because flux ingredients are not linearly independent of one another [75].

\subsection{Current Approaches to the Development of Prediction Models}

The DoE suitable for welding flux design appears unknown to WFDs until Kanjilal and coworkers applied a type of DoE known as mixture experiments to welding flux and used the experimental data to develop regression equations for the prediction of weld-metal chemical composition as a function of flux ingredients $\left(\mathrm{Al}_{2} \mathrm{O}_{3}, \mathrm{CaO}\right.$, $\mathrm{MgO}, \mathrm{CaF}_{2}$ ) [46]. The model fitted to their data was the Scheffes's quadratic canonical polynomial for overall curvature. Apart from the predictive ability of the regression models, they also provide information in terms of the magnitude and direction of individual flux ingredients effects as well as their binary interaction effects.

The success of their work in predicting the chemical composition of weld-metal and the insight it provided in understanding the nature of the relationship between the flux ingredients and response variables ignited the interest of researchers [13, 50, 53, 55, 75]. Sui et al. [13] fitted a second-order equation to pure mixture experiment data. The model predicted the flux softening temperature as a function of the flux ingredients. Kanjilal et al. [47] fitted a second-order model involving mixture related variables (flux ingredients) and welding process parameters to experimental data. The pure mixture experiment has gained more popularity in welding flux design than the mixture-process design. Many models have been proposed for weld-metal quality and welding process productivity such as weld-metal chemistry, microstructure, mechanical and thermophysical and physicochemical properties (see Table 3). Scheffe's models fail in situations where extreme changes occur in the response behaviour as one or more flux ingredient tends to a boundary of the simplex region. This kind of response behaviour is known as edge effect. They are also not 
able to model the combine effects of the additive nature of some ingredients and the curvilinear blending effects of the remaining ingredients [94]. Adeyeye and Oyawale [75] suggested some models that could address these limitations. Scheffe's cubic and special cubic were suggested for ternary interaction effects. Scheffe's model with inverse terms were suggested to cater for edge effects and Becker's models for combined additive and curvilinear flux blending effects. They also presented the sequential model build-ups that could be used to check for ternary interactions, edge and additive effects. The progress made in the development of prediction models, their benefits and the extent to which they have been explored in flux development are presented in Table 3.

\section{FLUX QUALITY ATTRIBUTES OPTIMISA- TION}

\subsection{The Traditional Approach to Flux Qual- ity Attribute Optimisation}

Optimisation involves identifying the proportion of welding flux ingredient that gives the best values of the required quality characteristics. It has been noted that the formulate-and-test approach (discussed in Section 2) to flux development is random and does not guarantee optimal flux formulation [10,75]. Usually the best flux from the formulate-and-test experiments is taken as the optimum. This is misleading because the choice is not based on the fulfilment of any optimality criteria as far as optimisation principles are concerned. The traditional formulate-andtest approach was needed because it was very difficult to know a priori how the flux ingredients, welding wire constituents and welding parameters interact to determine the weld-metal quality, operational efficiency and the productivity of the welding process. Also, the quality attributes the flux is expected to achieve are many and conflicting. The conflict arises because improvement on the achievement of one quality attribute often decreases the performance of the flux on one or more of the other attributes. Since it is not feasible to achieve a flux that attains the ideal levels of all quality attributes simultaneously, compromises and balances are often provided and designed into it. Until recently, lengthy and costly experiment has been the method of achieving the balances but such fluxes cannot be guaranteed to be the best compromise flux. The traditional method was a heuristic technique.

Ren et al. [86] made effort at obtaining optimal flux by using a DoE method known as Uniform Design (UD). The UD is based on uniform dispersion of the experimental points in the experimental region. The believe was that the best flux formulation from the experiment is the optimum since the experimental points are uniformly scattered and are more representative of the whole experimental space. Since it is not practical to explore all points in the experimental space, there is no guarantee that the flux developed by UD is optimum. The optimum flux formulation may not coincide with any of the experimental points. Even if it happens to coincide with an experimental point per chance, the UD does not provide any scientific means or optimality criteria for its identification other than the uniform scattering of experimental point. The lack of optimising algorithm for identification of optimum flux had been a major challenge of welding flux design [10]. Optimisation modelling solution approach was extremely difficult because of the complex reactions and interactions the welding flux ingredients, welding wire constituents and welding parameters exhibit during the welding process as well as the multiple and conflicting quality attributes involved. This appears to have precipitated difficulties of:

(i) constructing objective and constraint functions that adequately express the multiple flux quality specifications;

(ii) defining a feasible criterion space for systematic experimentation;

(iii) resolving conflicts arising from simultaneously satisfying the desirable multiple flux attributes; and

(iv) taking into consideration the preferences of the user.

\subsection{Current Approaches of Welding Flux Quality Attributes Optimisation}

\subsubsection{Single quality attribute optimisation}

Adeyeye and Oyawale [10] extended the works of Kanjilal et al. [46, 47, 53, 81] and Sui et al. [13] beyond mere prediction. They used mathematical programming approach for flux quality optimisation. Building on their work, they proposed mathematical programming models for determining the optimum flux composition for the case where the interest of a WFD is in a single quality attribute. They illustrated with three cases of beneficial quality attributes where higher values imply better performance (larger-the-best (LTB)). Optimisation models consisting of objective and constraint functions representing the flux formulation problem were constructed for each of the cases. The constraint functions defined the experimental region. The LTB cases were (i) maximise acicular ferrite content of weld-metal (ii) maximise Charpy impact toughness (iii) maximise silicon transfer. The models were solved to determine the flux formulation that gave maximum values of the quality attributes. They also illustrated with a case where oxygen content of weld-metal is nonbeneficial, that is, lower value indicates better performance (smaller-the-best (STB)). All the values obtained were better than those obtained by experiments. For instance, the highest acicular ferrite content from experiment was $36 \%$ while the optimising algorithm identified flux formulation that gave acicular content of $51.2 \%$. The optimising algorithm was able to search for the optimum flux ingredient levels within the experimental space even when it doesn't coincide with any of the experimental points. 
Table 2: Advances in application of DoE.

\begin{tabular}{lllc}
\hline S/N Year & Type of DoE & References \\
\hline 1 & 2004 & Mixture experiment & {$[46]$} \\
2 & 2006 & Rotatable mixture design (for flux ingredients and process parameters) & {$[47]$} \\
3 & 200 & 6 Uniform design & {$[86]$} \\
4 & 2008 & Hadamard Multivariate Design (HMD) & {$[87]$} \\
5 & 2008 & Mixture-Amount Design* & {$[75]$} \\
6 & 2010 & Nested Random Model (NRM) & {$[90]$} \\
7 & 2010 & Taguchi method & {$[5]$} \\
9 & 2015 & Response surface method & {$[6,21]$} \\
\hline
\end{tabular}

* Suggested but not yet implemented in welding flux development

Table 3: Trends in development of prediction modelling.

\begin{tabular}{|c|c|c|c|}
\hline $\mathbf{S} / \mathbf{N}$ & Model, Year and [Paper] & Quality Attribute & Usefulness \\
\hline 1 & $\begin{array}{l}\text { Scheffe's quadratic polynomial, } \\
2004[46]^{+++}\end{array}$ & $\begin{array}{l}\text { TC, SH, CA, SA, ST, WA, C, Si, Mn, P, } \\
\text { WL, UTS, YS, AF, GBF, SPF, PF, UB, } \\
\text { IVF, INF, WBP \%EL, Hardness. }\end{array}$ & $\begin{array}{l}\text { Prediction and binary in- } \\
\text { teractions }\end{array}$ \\
\hline 2 & $\begin{array}{l}\text { Second-order model with square } \\
\text { terms, } 2006[13]++\end{array}$ & Softening temperature & $\begin{array}{l}\text { Prediction and binary in- } \\
\text { teractions }\end{array}$ \\
\hline 3 & $\begin{array}{l}\text { Second-order model (mixture- } \\
\text { process variables), } 2006[47]^{++}\end{array}$ & $\begin{array}{l}\text { C, Si, Mn, P, S, Ni, YS, UTS, IT and } \\
\text { VHN }\end{array}$ & $\begin{array}{l}\text { Prediction and binary in- } \\
\text { teractions }\end{array}$ \\
\hline 4 & $\begin{array}{l}\text { Scheffe's linear model for planar } \\
\text { effects, } 2007\left[^{9}\right]^{++}\end{array}$ & TD, Density & $\begin{array}{l}\text { Prediction and individual } \\
\text { effects }\end{array}$ \\
\hline 5 & $\begin{array}{l}\text { Scheffe's cubic for third order } \\
\text { asymmetric curvature, } 2008 \\
{[75]^{++}}\end{array}$ & Change in enthalpy & $\begin{array}{l}\text { Prediction and ternary in- } \\
\text { teraction effects }\end{array}$ \\
\hline 6 & $\begin{array}{l}\text { Scheffe's special cubic for third or- } \\
\text { der curvature, } 2008[75]^{++}\end{array}$ & AE, SA, TC, TD, SH, Density, & $\begin{array}{l}\text { Prediction and ternary in- } \\
\text { teraction effects }\end{array}$ \\
\hline 7 & $\begin{array}{l}\text { Scheffe's linear plus inverse } \\
\text { terms, 2008 [75] }\end{array}$ & Yet to be explored & Prediction (edge effects) \\
\hline 8 & $\begin{array}{l}\text { Scheffe's quadratic plus inverse } \\
\text { terms, } 2008[75]\end{array}$ & Yet to be explored & Prediction (edge effects) \\
\hline 9 & $\begin{array}{l}\text { Scheffe's cubic plus inverse terms, } \\
2008 \text { [75] }\end{array}$ & Yet to be explored & Prediction (edge effects) \\
\hline 10 & $\begin{array}{l}\text { Scheffe's special cubic plus in- } \\
\text { verse terms, 2008 [75] }\end{array}$ & Yet to be explored & $\begin{array}{l}\text { Prediction (models edge ef- } \\
\text { fects). }\end{array}$ \\
\hline 11 & $\begin{array}{l}\text { Becker's homogeneous models, } \\
2008[75]\end{array}$ & Yet to be explored & Prediction (additive effects) \\
\hline 12 & $\begin{array}{l}\text { Linear model of mixture and pro- } \\
\text { cess variables, } 2008[75]\end{array}$ & Yet to be explored & Prediction \\
\hline
\end{tabular}

${ }^{+++}$Has received much attention, ${ }^{++}$Has received little attention, TD=Thermal diffusivity, $\mathrm{TC}=$ Thermal conductivity, $\mathrm{SH}=$ Specific heat, $\mathrm{CA}=$ Contact angle, $\mathrm{SA}=$ Spread area, $\mathrm{ST}=$ Surface tension, WA=Work of adhesion, WL=Weight loss, IT=Impact toughness, UTS=Ultimate tensile strength, VHN= Vickers hardness, $\mathrm{YS}=$ Yield strength, $\mathrm{AF}=\mathrm{Acicular}$ ferrite, $\mathrm{GBF}=$ Grain boundary ferrite, $\mathrm{SPF}=$ Side plate ferrite, $\mathrm{PF}=\mathrm{Polyg}$ onal ferrite, $\mathrm{UB}=\mathrm{Upper}$ bainite, IVF=Inclusion volume fraction, $\mathrm{AE}=\mathrm{Adh}$ esion energy $\mathrm{WBP}=\mathrm{Weld}$ bead parameter, $\mathrm{INF}=$ Inclusion number fraction, $\% \mathrm{EL}=$ Percentage elongation.

Table 4: Trends in optimisation methods.

\begin{tabular}{ll}
\hline Year [Reference] & Optimisation method \\
\hline $2009[10]$ & Single flux attribute for LTB and STB cases \\
$\begin{array}{l}2010 \text { [96] (multiple attributes with com- } \\
\text { parable importance) }\end{array}$ & $\begin{array}{l}\mathrm{WSS}^{++} \text {(for LTB and STB cases); DF (for LTB, STB \& NTB }{ }^{+} \text {); NGP } \\
\text { (for Target values); CP (Minimum distance from ideal) }\end{array}$ \\
2010 [96] & $\mathrm{PGP}^{++}$(for attributes at different priority levels) \\
\hline
\end{tabular}

+ Nominal-the-best

++ Suggested but not yet implemented 
Apart from showing the flux ingredient levels that achieved the optimum levels of flux quality performance, the approach also provided insight as to maximum and minimum values that are attainable for each of the flux quality attributes under the existing conditions for beneficial and nonbeneficial attributes respectively. This could be used to establish the feasibility of developing a flux that can achieve a given performance level. For example, if there is the need to produce flux that will deposit weld-metal with acicular ferrite content above $51.2 \%$, the WFD knows immediately that it is not feasible under the prevailing conditions. This is an additional advantage over the traditional approach where feasibility could not be established until a lot of time and resources have been expended on formulate-and-test experiments. The single quality attribute optimisation addressed two of the issues, namely, (i) construction of objective function that defines the goal of the WFD and constraint functions that define the experimental space (ii) Establishment of feasibility.

\subsubsection{Multiple quality attribute optimisation}

Welding flux design situations involving multiple quality attributes are encountered more frequently than the single quality attribute case. To address the multi-attribute flux formulation cases, Adeyeye and Oyawale [96] identified two major classifications, namely (i) cases where the flux quality attributes are of comparable importance and (ii) situations where one or more quality attribute(s) are of overriding importance when compared to others. The procedure for the development of optimisation models and the flux formulation situations where each could be useful were discussed. Four of the methods were proposed for situations where the attributes are of comparable importance: (i) Weighted Sum Scalarisation (WSS) (ii) Desirability Function (DF) (iii) Non-pre-emptive Goal Programming (NGP) and (iv) Compromise Programming (CP). Pre-emptive Goal Programming (PGP) was suggested for welding flux design situation where the attributes are in hierarchical order of importance because some attributes are of overwhelming importance when compared to others.

These methods addressed the problems that had hitherto persisted in welding flux development, namely (i) difficulty of handling several conflicting flux attributes simultaneously (ii) the problem of identifying the best compromise for welding flux formulation (iii) lack of quantitative means of carrying out trade-off exploration. The specific areas where each of the multiple attribute optimisation methods could be useful are presented in Table 4.

Since the appearance of the work of Adeyeye and Oyawale [10, 18, 95] on application of optimisation methods to welding flux design, interest of researchers in flux optimisation has been growing and it is expected that the growth will continue. Despite the growing interest only DF method has received significant attention by weld- ing flux researchers $[19,24,62-67,82,85]$. This could be because statistical packages used in designing experiments has built-in solver for DF. The other approaches require a different package and some knowledge of optimisation model development. The applications of NGP and CP methods have received sparing attention while the exploration of WSS and PGP methods are yet to appear in the open literature $[18,96]$. The reason might be that WFD are either not familiar with these methods or the applicability and efficacy are not clear to them. The idea of determination of feasible attribute solution space introduced by Adeyeye and Oyawale [10] for single attribute optimisation is also yet to be properly addressed for the case of multi-attribute welding flux design situation.

\section{CONCLUSIONS AND FUTURE PROSPECTS}

In the following sub-sections, some conclusions on the three main topics representing the most active areas of advances is presented.

\subsection{Experimentation}

The belief in the past was that factorial design and the type of Response Surface Method (RSM) commonly used in other areas of arc welding technology are not applicable in welding flux development because welding flux properties depend on the relative proportions of the ingredients. The choice of ingredient levels is not independent and must sum up to unity or $100 \%$ [75]. Mixture designs were developed by researchers to handle experimental design cases where predictor variables are linearly dependent. However, recent applications have shown that it is possible to adapt Hadamard multivariate design, nested random model design, response surface and Taguchi methods for flux development and still ensure that at each of the experimental points in the flux ingredient space, the total sum of the proportions of all the ingredients adds up to unity $[5,6,21,55,87,90]$.

The thickness of flux coating (coating factor) for SMAW and flux height in the case of SAW contribute to the quality of weld-metal and productivity of the welding process. The coating factor and flux height are related to amount of flux. It was for this reason Adeyeye and Oyawale [75] suggested mixture-amount design for flux formulation. Studies that incorporates amount of flux and flux proportions are scanty in the open literature. The exploration of mixture-amount design for flux development hold some promise for the future.

\subsection{Predictive Modelling}

Majority of models proposed to date are quadratic and are only able to identify and quantify binary interaction effects. The Scheffe's models are generally adequate for modelling well behaved flux systems. They however, fail in some situations. As mentioned in Section 3, instances where extreme changes occur in the behaviour of some responses as some ingredients approach boundary values is a very real occurrence in many mixture experimentations. This is known as edge 
effect. Another real occurrence in blending experiment is that some ingredients serve as diluent in the sense that an increase in the proportion of such ingredients reduce the effect of the remaining ingredients on the response. Scheffe's quadratic canonical polynomial for overall curvature used by Kanjilal et al. [46] could not satisfactorily fit the experimental data for carbon, phosphorus and nitrogen contents of the weld-metal in the particular case they studied. It could probably be as a result ignoring either higher order interactions, edge effects or additive effects or a combination of any two or all. Application of Scheffe's quadratic model proposed by Kanjilal et al. [46] has gained much attention in welding flux development [19, 22, 56, 62-67, 82, 85]. Scheffe's cubic and special cubic models suggested for welding flux development by Adeyeye and Oyawale [75] started getting attention recently and have been used for prediction and explanation of main, binary and ternary interaction effects of flux ingredients but those suggested for edge and additive effects are yet to be explored [62, 63, 66, 67]. They are therefore recommended for further studies.

\subsection{Optimisation}

\subsubsection{Relative importance of quality attributes}

Most of the applications of the optimisation models to date have assumed equal importance for all attributes. This is not so in real world optimisation problems. Cases where attributes are of equal importance are not as common as cases where they are of different importance. As far as we know, only Adeyeye and Oyawale [18] and Adeyeye and Allu [96] employed quantitative and systematic approach of incorporating the preferences of WFD in terms of relative importance he/she attaches to the attributes. The respective methods used were pairwise comparison and analytical hierarchy process. More research efforts are needed at identifying and incorporating WFD's estimation of the relative importance of various quality attributes. Furthermore, most of the work done to date have assumed that the quality attributes are all at the same level. As demonstrated by Adeyeye and Oyawale [96], some attributes could be bundles of other attributes. For instance, a primary attribute may be broken down to secondary or sub-attributes while the sub-attributes may further be broken down to tertiary/sub-sub-attributes. This is a challenge that is yet to be addressed. Also, cases where some attributes are of overriding importance compare to others requires different optimisation approaches because they are in different priority levels. Although Adeyeye and Oyawale [18] have suggested pre-emptive goal programming for such instances, it is yet to be explored by WFDs.

\subsubsection{Feasible attribute space}

Identification and definition of feasible attribute space was mentioned by Adeyeye and Oyawale [10,18] but not well developed for multiattribute case. Because of high cost of welding wire, welding electrode designers often use the same wire to achieve different weld deposit by merely changing the proportions of the flux ingredients. By using different proportions of ingredients, it is possible to develop an infinite variety of welding flux. When it is required that a new flux be developed for the same wire to achieve a different set of weld-metal properties, the WFD often embark on lengthy formulate-and-test experimentation with its attendant drawbacks. The challenge of lack of means of determining the feasibility of achieving the desire weld-metal properties has persisted for long in welding flux technology. It is unlikely that the WFD will be able to rise to this challenge without better tools with which he can determine the attainable set or the feasible attribute space. As a result of the absence of right tools the WFD is not able to know whether or not it is possible to achieve the desired properties within the experimental domain until a lot of resources have been expended on experiments. At times, a lot of resources are consumed searching for flux formulation that will achieve desired specifications in an experimental domain even when such formulation may not exist in that experimental region. On the other hand, the desired formulation may exist within the experimental domain but the WFD may not be able to identify it through the try-and-test experiments because of its random nature. The WFD often abandons the experimental domain to establish a new domain with the erroneous impression that the desired flux formulation cannot be achieved or does not exist within the experimental space because he has not been able to identify it after a series of tedious experiments. Identification of feasible quality attribute space will help the WFD to make intelligent decision on either to go ahead with the same flux ingredients or not. Determination of feasible attribute space should be part of research focus for the future.

\subsubsection{Models and trade-off surface}

The regression functions defining the flux quality attributes are assumed to be continuous and smooth over the domain of interest. It is also assumed that the best compromise flux is located at the convex region of the criterion space. Situations where the response functions are not continuous and some solutions are located at concave regions of the trade-off surface should be a focus of future studies.

\section{References}

[1] W. Spraragen, "Fluxes and slags in welding," Transactions of the Faraday Society, vol. 20, pp. 168-175, 1924.

[2] R. K. Chandra, M. Majid, H. K. Arya, and A. Sonkar "Improvement in tensile strength and microstructural properties of saw welded low alloy steels by addition of titanium and manganese in agglomerated flux," J. Material Sci. Eng., vol. 5, no. 4, pp. 1-5, 2016.

[3] S. S. Singh and B. J. Singh, "An optimistic approach to blend recycled-slag with flux: a step towards green SAW," Int. J. Process Management and Benchmarking, vol. 6, no. 3, pp. 300-327, 2016.

[4] G. Hunter, G. B. Kenney, M. Ring, B. A. Russel, and T. W. Eagar, "Submerge arc welding of titanium," Submitted to Office of Naval Research, USA, Tech. Rep. 3, 1979. 
[5] V. Kumar, N. Mohan, and J. S. Khamba, "Development of agglomerated acidic flux for submerged arc welding," Estonian Journal of Engineering, vol. 16, no. 2, pp. 135$14,2010$.

[6] S. S. Somal, N. S. Turna, T. S. Grewal, and G. S. Thind, "Comparative analysis of tensile strength and percentage elongation in submerged arc welding using different slag-flux ratios," International Journal of Innovative Research in Science, Engineering and Technology, vol. 4, no. 9, pp. 8912-8921, 2015.

[7] J. Garg and K. Singh, "Slag recycling in submerged arc welding and its effects on the quality of stainless-steel claddings," j.matdes, vol. 108, pp. 689-698, 2016.

[8] M. Kumar, V. Pilania, G. Kumar, and R. Chandra, "Effect of adding different powders in saw agglomerated flux on the mechanical properties of 1025 welds," IAETSD Journal for Advanced Research in Applied Sciences, vol. 5, no. 5, pp. 158-167, 2018.

[9] W. N. Khan, J. Kumar, and R. Chhibber, "Hightemperature wettability study of mineral waste added $\mathrm{CaO}-\mathrm{CaF}_{2}-\mathrm{SiO}_{2}$ and $\mathrm{CaO}-\mathrm{TiO}_{2}-\mathrm{SiO}_{2}$-based electrode coating for offshore welds, Journal of Materials: Design and Applications, vol. 234, no. 4, pp. 622-636, 2020.

[10] A. D. Adeyeye and F. A. Oyawale, "Weld-metal property optimization from flux ingredients through mixture experiments and mathematical programming approach," Materials Research, vol. 12, no. 3, pp. 339-343, 2009.

[11] A. D. Adeyeye, G. O. Odu, and O. E. Charles-Owaba, "Adaptation of compromise programming approach for multi-criteria material selection," American Journal of Engineering Research, vol. 4, no. 6, pp. 112-122, 2015.

[12] R. Kohno, T. Takami, N. Mori, and K. Nagano, "New fluxes of improved weld metal toughness for HSLA steels," Welding Journal, vol. 12, no. 12, pp. 373s-380s, 1982.

[13] S. Sui, W. Cai, Z. Liu, T. Song, and A. Zhang, "Effect of submerged arc welding flux component on softening temperature," Journal of Iron and Steel Research, International, vol. 13, no. 2, pp. 65-68, 2006.

[14] C. R. Gómez-Pérez, A. Paula-Perotti, A. GarcíaRodríguez, J. A. Esmerio-Mazzaferro, A. RubénGonzalez, and I. Guerra-Machado, "Mc. Lean-Anderson design applied for recovered electrodes obtaining with Carbon, Chrome and Titanium alloys," Ingeniería Mecánica, vol. 16, no. 2, pp. 132-143, 2013.

[15] A. Singh, S. Datta, S. S. Mahapatra, T. Singha, and G. Majumdar, "Optimization of bead geometry of submerged arc weld using fuzzy based desirability function approach," J. Intell. Manuf., vol. 24, pp. 35-44, 2013.

[16] E. K. Sharma, "Enrichment of flux by nickel to improve impact strength in submerged arc welding," IJITKM Special, no. ICFTM-2014, pp. 238-244, 2011.

[17] K. Sham and S. Liu, "Flux coating development for SMAW consumable electrode of high nickel alloys," Welding Journal, vol. 93, no. 8, pp. 271s-281s, 2014.

[18] A. D. Adeyeye and F. A. Oyawale, "Optimisation of weldmetal chemical composition from welding-flux ingredients: a non-pre-emptive goal programming approach," Maejo International Journal of Science and Technology, vol. 4, no. 2, pp. 347-359, 2010.

[19] S. Jindal, R. Chhibber, and N. P. Mehta, "Modeling flux chemistry for submerged arc weldments of highstrength low-alloy steel," Proc IMechE Part B: J Engineering Manufacture, vol. 228, no. 10, pp. 1259-1272, 2014.

[20] S. Datta, R. K. Sahu, and S. S. Mahapatra, "Optimisation of percent dilution and haz width of submerged arc weldment using taguchi philosophy coupled with fuzzy inference system," Int. J. Productivity and Quality Management, vol. 13, no. 4, pp. 430-49, 2014.

[21] G. Singh, V. Mishra, and S. Yadav, "Effect of developed flux and process parameters on hardness of weld in SAW," International Journal of Science, Technology \& Management, vol. 4, no. 1, pp. 1401-1406, 2015.

[22] D. Bhandari, R. Chhibber, N. Arora, and R. Mehta, "Investigation of $\mathrm{TiO}_{2}-\mathrm{SiO}_{2}-\mathrm{CaO}-\mathrm{CaF}_{2}$ based electrode coatings on weld metal chemistry and mechanical behaviour of bimetallic welds," Journal of Manufacturing Processes, vol. 23, pp. 61-74, 2016.
[23] B. Singh, "The correlation of weld microstructure and properties with element transfer in saw welds," Journal of Production Engineering, vol. 20, no. 1, pp. 97-100, 2017.

[24] L. Sharma and R. Chhibber, "Design and development of submerged arc welding slags using cao-sio ${ }_{2}$-caf 2 and cao-Sio -al $_{2} \mathrm{O}_{3}$ system," Silicon, vol. 11 , no. 6, pp. $2763-$ 2773,2019

[25] M. Matsushita and S. Liu, "Hydrogen control in steel weld metal by means of fluoride additions in welding flux," Welding Journal, vol. 79, no. 10, pp. 295s-303s, 2000

[26] J. Du Plessis, M. Du Toit, and P. C. Pistorious, "Reducing the diffusible hydrogen content of shielded metal arc welds by means of fluoride and calcite flux additions," International Institute of Welding, 2006, iIW Document II-1590-06 (II-A-172r1-06).

[27] - "Control of diffusible weld metal hydrogen through flux chemistry modification," Welding Journal, vol. 86, no. 9, pp. 273s-280s, 2007

[28] J. Du Plessis and M. Du Toit, "Reducing diffusible hydrogen content of shielded metal arc welds through addition of flux-oxidizing ingredients," Journal of Materials Engineering and Performance, vol. 17, no. 1, pp. 50-56, September 2008

[29] H. Terashima and J. Tsuboi, "Hydrogen in submerged arc weld metal produced with agglomerated flux," Welding Journal of Japan, vol. 45, pp. 28-33, 1976.

[30] E. Surian, "ANSI/AWS E7024 SMAW electrode: The effect of coating magnesium additions, part 1: on operational behaviour, diffusible hydrogen and allweld-metal mechanical properties and microstructure," Welding Journal, vol. 76, no. 10, pp. 404s-411s, 1997.

[31] L. Reeve, "The relation between the hydrogen content of weld metal and its oxygen content," The Journal of the Iron and Steel Institute, vol. 202, no. 2, pp. 385-396, 1945.

[32] S. Liu, D. L. Olson, and S. Ibara, Under water welding, brazing and soldering, 9th ed., Materials Park Ohio, 1993.

[33] A. Pope and S. Liu, "Hydrogen content of underwater wet welds deposited by rutile and oxidizing electrodes," Materials Engineering ASME OMAE, vol. 3, pp. 85-93, 1996

[34] E. Baune, C. Bonnet, and S. Liu, "Reconsidering the basicity of a fcaw consumable as a basicity indicator part 1," Welding Journal, vol. 79, no. 3, pp. 57s-65s, 2000.

[35] T. H. North, H. B. Belt, A. Nowicki, and I. Craig, "Slag/metal interaction, oxygen and toughness in submerged arc welding," Welding Journal, vol. 57, no. 3, pp. $63 \mathrm{~s}-75 \mathrm{~s}, 1978$.

[36] E. Baune, C. Bonnet, and S. Liu, "Reconsidering the basicity of a fcaw consumable - part 2: Verification of the flux/slag analysis methodology for weld metal oxygen control," Welding Journal, vol. 79, no. 3, pp. 66-71, 2000

[37] V. Kumar, N. Mohan, and J. S. Khamba, "Development of cost-effective agglomerated fluxes from waste flux dust for submerged arc welding," London, U.K, July 2009 , pp. 87-93.

[38] N. T. Jenkins and T. W. Eagar, "Chemical analysis of welding fume particles," Welding Journal, vol. 84, no. 6 , pp. 87-93, 2005.

[39] S. McCarrick, Z. Wei, N. Moelijker, R. Derr, K. Persson, G. Hendriks, I. O. Wallinder, Y. Hedberg, and H. L. Karlsson, "High variability in toxicity of welding fume nanoparticles from stainless steel in lung cells and reporter cell lines: the role of particle reactivity and solubility," Nanotoxicology, vol. 13, no. 10, pp. 1293-1309, 2019.

[40] P. C. Zeidler-Erdely, L. M. Falcone, and J. M. Antonini, "Influence of welding fume metal composition on lung toxicity and tumor formation in experimental animal models," Journal of Occupational and Environmental Hygiene, vol. 16, no. 6, pp. 372-377, 2019

[41] S. Mohan, S. P. Sivapirakasam, M. C. S. Kumar, and M. Surianarayanan, "Welding fumes reduction by coating of nano-TiO ${ }_{2}$ on electrodes," Journal of Materials Processing Technology, vol. 219, pp. 237-247, 2005. 
[42] S. P. Sivapirakasam, S. Mohan, M. C. S. Kumar, and M. Surianarayanan, "Welding fume reduction by nanoalumina coating on electrodes towards green welding process," Journal of Cleaner Production, vol. 108, pp. 131-144, 2015.

[43] S. P. Sivapirakasam, S. Mohan, M. C. S. Kumar, A. T. Paul, and M. Surianarayanan, "Control of exposure to hexavalent chromium concentration in shielded metal arc welding fumes by nano-coating of electrodes," International Journal of Occupational and Environmental Health, vol. 23, no. 2, pp. 128-142, 2017.

[44] B. Vishnu, S. P. Sivapirakasam, K. K. Satpathy, S. K. Albert, and G. Chakraborty, "Influence of nano-sized flux materials in the reduction of the $\mathrm{cr}$ (vi) in the stainless-steel welding fumes,"Journal of Manufacturing Processes, vol. 3, pp. 713-720, 2018.

[45] S. P. Sivapirakasam, S. Mohan, M. C. S. Kumar, A. T. Paul, and M. Surianarayanan, "Control of exposure to hexavalent chromium concentration in shielded metal arc welding fumes by nano-coating of electrodes," International Journal of Occupational and Environmental Health, vol. 23, no. 2, pp. 128-142, 2018.

[46] P. Kanjilal, S. K. Majumder, and T. K. Pal, "Prediction of submerged arc weld-metal composition from flux ingredients with the help of statistical design of mixture experiment," Scandinavian Journal of Metallurgy, vol. 33, pp. $146-159,2004$.

[47] P. Kanjilal, S. K. Majumder, and T. K. T. K. Pal, "Weld metal microstructure prediction in submerged arc weld metal of C-Mn steel," Steel Research International, vol. 77, no. 7, pp. 512-523, 2006.

[48] A. Gupta, P. K. Sapra, N. Singla, and G. Ram, "Effect of various flux compositions mixed with slag on mechanical properties of structural steel weld using submerged arc welding," Asian Review of Mechanical Engineering, vol. 2, no. 2, pp. 27-31, 2013.

[49] P. Kanjilal, S. K. Majumder, and T. K. Pal, "Prediction of acicular ferrite from flux ingredients in submerged arc weld metal of c-mn steel," ISIJ International, vol. 45, no. 6 , pp. 876-885, 2005 .

[50] L. Sharma and R. Chhibber, "Mechanical properties and hydrogen induced cracking behaviour of API X70 SAW weldments," International Journal of Pressure Vessels and Piping, vol. 165, pp. 193-207, 2018.

[51] N. D. Pandey, A. Bharti, and S. R. Gupta, "Effect of submerged arc welding parameters and fluxes on element transfer behaviour and weld metal chemistry," Journal of Materials Processing Technology, vol. 40, pp. 195$211,1994$.

[52] K. Bang, C. Park, H. Jung, and J. Lee, "Effects of flux composition on the element transfer and mechanical properties of weld metal in submerged arc welding," Met. Mater. Int., vol. 15, no. 3, pp. 471-477, 2009.

[53] P. Kanjilal, S. K. Majumder, and T. K. Pal, "Prediction of element transfer in submerged arc welding," Welding Journal, vol. 86, no. 5, pp. 135s-148s, 2007.

[54] B. Singh, Z. A. Khan, A. N. Siddiquee, and S. Maheshwari, "Experimental study on effect of flux composition on element transfer during submerged arc welding," Sådhanå, vol. 43 , no. 26 , pp. 1-12, 2018.

[55] J. I. Achebo "Development of compositions of aluminium welding fluxes using statistical method," in Proceedings of the 2nd International Multiconference of Engineers and Computer Scientists (IMECS), Hong Kong, March 2009.

[56] S. C. Nwigbo and C. U. Atuanya, "Formulation of a metal arc welding flux with a potash enriched sodium silicate binder," Journal of Emerging Trends in Engineering and Applied Sciences, vol. 3, no. 3, pp. 497-501, 2012.

[57] A. Kumar, H. Singh, and S. Maheshwari, "Modeling and analysis by response surface methodology of hardness for submerged arc welded joints using developed agglomerated fluxes," Indian Journal of Engineering and Materials sciences, vol. 19, pp. 379-385, 2012.

[58] A. Kumar and S. Maheshwari, "Optimization of submerged arc welding rutile based flux constituents by hybrid grey, fuzzy and taguchi analysis," Advanced Materials Manufacturing and Characterization, vol. 5, no. 2, pp. 63-70, 2015.
[59] B. Singh, "Fuzzy logic optimization for low sulphur and phosphorus in submerged arc weldments," Journal of Welding and Joining, vol. 35, no. 6, pp. 67-72, 2017.

[60] D. Verma, M. Garg, and R. P. Singh, "Effect of performance parameters with different flux composition on weld bead geometry during submerged arc welding (SAW) of steel," International Journal of Engineering Sciences \& Research Technology, vol. 4, no. 4, pp. 614620,2015

[61] S. Choudhary, R. Shandley, and A. Kumar, "Optimization of agglomerated fluxes in submerged arc welding," Materials Today, vol. 5, no. 2, pp. 5049-5057, 2018.

[62] L. Sharma and R. Chhibber, "Design \& development of SAW fluxes using $\mathrm{CaO}-\mathrm{SiO}_{2}-\mathrm{CaF}_{2}$ and $\mathrm{CaO}-\mathrm{SiO}_{2}-\mathrm{Al}_{2} \mathrm{O}_{3}$ flux systems," Ceramics International, vol. 46, no. 2, pp. 1419-1432, 2020.

[63] L. Sharma, J. Kumar, and R. Chhibber, "Experimental investigation on high temperature wettability and structural behaviour of SAW fluxes using $\mathrm{MgO}-\mathrm{TiO}_{2}-\mathrm{SiO}_{2}$ and $\mathrm{Al}_{2} \mathrm{O}_{3}-\mathrm{MgO}-\mathrm{SiO}_{2}$ flux system," Ceramics International, vol. 46 , no. 5 , pp. 5649-5657, 1209.

[64] - "Experimental investigation on surface behaviour of submerged arc welding fluxes using basic flux system," Ceramics International, vol. 46, no. 6, pp. 81118121,2019

[65] S. Mahajan, J. Kumar, and R. Chhibber, "HighTemperature Wettability Investigations on LaboratoryDeveloped $\mathrm{CaO}-\mathrm{CaF}_{2}-\mathrm{SiO}_{2}-\mathrm{Al}_{2} \mathrm{O}_{3}$ Flux System-Based Welding Electrode Coatings for Power Plant Applications," Silicon, vol. 12, pp. 2741-2753, 2020.

[66] S. Mahajan and R. Chhibber, "Design and development of shielded metal arc welding (SMAW) electrode coatings using a $\mathrm{CaO}-\mathrm{CaF}_{2}-\mathrm{SiO}_{2}$ and $\mathrm{CaOSiO}_{2}-\mathrm{Al}_{2} \mathrm{O}_{3}$ flux system," JOM, vol. 71, no. 7, pp. 2435-2444, 2020.

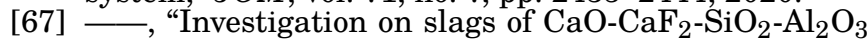
based electrode coatings developed for power plant welds," Ceramics International, vol. 46, no. 7, pp. 8774$8786,2020$.

[68] S. Datta, A. Bandyopadhyay, and P. K. Pal, "Slag recycling in submerged arc welding and its influence on weld quality leading to parametric optimization," Int. J. Adv. Manuf. Technol, vol. 39, pp. 229-238, 2008.

[69] D. Mahto and A. Kumar, "Novel method of productivity improvement and waste reduction through recycling of submerged arc welding slag," Jordan Journal of Mechanical and Industrial Engineering, vol. 4, no. 4, pp. $451-466,2010$

[70] K. Singh and S. Pandey, "Recycling of slag to act as a flux in submerged arc welding," Resources, Conserva tion and Recycling, vol. 53, no. 10, pp. 552-558, 2009.

[71] V. Kumar N. Mohan and J. S. Khamba "Development of cost-effective agglomerated fluxes from waste flux dust for submerged arc welding," in Proceedings of the World Congress on Engineering, vol. 1, 2009, pp. 561565.

[72] V. Kumar, "Use of response surface modeling in prediction and control of flux consumption in submerged arc weld deposits," in Proceedings of the 2nd World Congress on Engineering and Computer Science (2WCECS), vol. 1, San Francisco, October 2011.

[73] A. Kumar, S. Maheshwari, and S. K. Sharma, "Fuzzy logic optimization of weld properties for saw using silica based agglomerated flux," Procedia Computer Science, vol. 57, pp. 1140-1148, 2015.

[74] C. S. Yoon and J. H. Kim, "Generation rate and content variation of manganese in stainless steel welding," Journal of the Korean Soc. Occup. Environ. Hyg. vol. 16 , no. 3, pp. 254-263, 2006 .

[75] A. D. Adeyeye and F. A. Oyawale, "Mixture experiments and their applications in welding flux design," Journal of the Braz. Soc. of Mech. Sci. \& Eng., vol. 30, no. 4, pp. $319-326,2008$

[76] D. A. Fleming, A. Q. Bracarense, S. Liu, and D. L. Olson, "Toward developing a SMA welding electrode for HSLA-100 grade steel,"Welding Journal, vol. 75, no. 6, pp. 171s-183s, 1996

[77] R. M. N. De Rissone, E. S. Surian, R. H. Conde, and L. A. de Vedia, "Effect of slag variations on ANSI/AWS A5.1-91 E6013 electrode properties: replacement of 
$\mathrm{TiO} 2$ in electrode coating with $\mathrm{MnO}, \mathrm{FeO}, \mathrm{CaO}, \mathrm{MgO}$, $\mathrm{K}_{2} \mathrm{O}$, or $\mathrm{Na}_{2} \mathrm{O}$," Science and Technology of Welding \& Joining, vol. 6, no. 5, pp. 323-329, 2001.

[78] N. M. R. De Rissone, J. P. Farias, I. De Souza Bott, and E. S. Surian, "ANSI/AWS A5.1-91 E6013 rutile electrodes: The effect of calcite," Welding Journal, vol. 81, no. 7, pp. 113-124, 2002.

[79] E. C. P. Pessoa, A. Q. Bracarense, and S. Liu, "Exothermic additions to the tubular covered electrode and oxidizing reactions influence on underwater wet welding," in 26th International Conference on Offshore Mechanics and Arctic Engineering (OMAE2007-29734), June 2007.

[80] C. C. Ugoamadi, "Production of manual metal arc welding electrodes with local raw materials," Nigerian Journal of Technology, vol. 29, no. 1, pp. 121-125, 2010.

[81] S. Jindal, R. Chhibber, N. P. Mehta, and P. Kumar, "Design and development of fluxes for submerged arc welding of HSLA steel." International Journal of Surface Engineering and Materials Technology, vol. 3, no. 1, pp. $52-58,2013$.

[82] L. Sharma and R. Chhibber, "Design of $\mathrm{TiO}_{2}-\mathrm{SiO}_{2}-\mathrm{MgO}$ and $\mathrm{SiO}_{2}-\mathrm{MgO}-\mathrm{Al}_{2} \mathrm{O}_{3}$ based submerged arc fluxes for multipass bead on plate pipeline steel welds," Journal of Pressure Vessel Technology, vol. 141, no. 4, 2019.

[83] A. Kumar, H. Singh, and S. Maheshwari, "Modeling and analysis of elongation for submerged arc-welded joints by using developed agglomerated fluxes," Proc. IMechE Part B: J Engineering Manufacture, vol. 227, no. 7, pp. 1005-1012, 2013 .

[84] S. Jindal, R. Chhibber, and N. P. Mehta, "Prediction of element transfer due to flux and optimization of chemical composition and mechanical properties in highstrength low-alloy steel weld," Proc. IMechE Part B: J. Engineering Manufacture, 2014.

[85] D. L. Ren, B. Liao, C. Xu, L. Hu, and F. R. Xiao, "High notch toughness agglomerated flux for submerged arc welding of pipeline steel," Key Engineering Materials, vol. 306, pp. 405-410, 2006.

[86] J. I. Achebo and A. O. A. Ibhadode, "Development of a new flux for Aluminium gas welding" in Advanced Materials Research, Z. Y. Shen, M. N. James, W. D. Li, and Y. X. Zhao, Eds., 2008, pp. 677-684.

[87] J. I. Achebo, "A multiphysics analysis of aluminium welding flux composition optimization methods," in Advances in Computer Science and Engineering, S. Matthias, Ed. IntechOpen, 2011, pp. 215-236.

[88] A. O. Abdulsalam, A. O. Ibrahim, and E. Vincent, "Formulation and production of arc welding electrode coated with mill scale based flux locally sourced from Ajaokuta steel company limited in Nigeria," International Journal of Advanced Engineering, Management and Science, vol. 6, no. 3, pp. 111-116, 2020.

[89] J. I. Achebo, "Optimizing stoichiometric welding fluxes using nested random model," in DAAAM International Scientific Book, B. Katalinic, Ed. Vienna, Austria: DAAAM International, 2010, pp. 377-394.

[90] A. Kumar, "Study of Element Transfer for Silica Based Flux Constituents by Taguchi Analysis in Submerged Arc Welding," International Journal of Research, vol. 8, no. 1, pp. 149-152, 2019.

[91] K. U. Akay, "A note on model selection in mixture experiments," Journal of Mathematics and Statistics, vol. 3, no. 3, pp. 93-99, 2007.

[92] T. W. Eager, "Sources of weld metal oxygen contamination during submerged arc welding," Welding Journal, vol. 57 , no. 3, pp. 76-80, 1978.

[93] A. C. Crespo, R. Q. Puchol, L. P. Goncalez, L. G. Sanchez, P. C. R. Gomez, E. D. Cedre, T. O. Mendez, and J. A. Pozol, "Obtaining a submerged arc welding flux of the $\mathrm{MnO}-\mathrm{SiO}_{2}-\mathrm{CaO}-\mathrm{Al}_{2} \mathrm{O}_{3}-\mathrm{CaF}_{2}$ system by fusion," Welding International, vol. 21, no. 7, pp. 502-511, 2007.

[94] J. P. Farias, A. Scotti, P. S. Balsamo, and E. Surian, "The effect of wollastonite on operational characteristics of aws e6013 electrodes," Journal of the Brazilian Society of Mechanical Science and Engineering, vol. 26, no. 3, pp. 317-322, 2004.

[95] A. D. Adeyeye and F. A. Oyawale, "Multi-objective methods for welding flux performance optimization," $R M Z$ Materials and Geoenvironment, vol. 57, no. 2, pp. 251270,2010 .
[96] A. D. Adeyeye and A. J. Allu, "A compromise programming approach to welding flux performance optimization," in Proc. of the Int. Conf. on Industrial Engineering and Operations Management, Bogota, Colombia, October 2017, pp. 53-63. 